\title{
WhatsApp in Acta Haematologica?
}

\author{
Pia Raanani \\ Hematology Division, Davidoff Cancer Center, Beilinson Hospital, Rabin Medical Center, Petah Tikva, Israel
}

It is with great pleasure that I would like to update our readers on last year's changes and achievements.

I am happy to present our new Editorial Office team: Steffi Hentzelt - Publication Manager, Shelly Shochat Editorial Office Specialist, and Denise Frey - Production Editor.

We welcome the new Editorial Board members who joined us last year. All are leading figures in their field: Dr. Arina ten Cate-Hoek from Maastricht University Medical Center, Netherlands; Dr. Noel Chan from McMaster University, Canada; Dr. Alison Moskowitz from Memorial Sloan Kettering Cancer Center, USA; Dr. Nicholas Short from MD Anderson Cancer Center, USA, and Dr. Deborah Rund from the Hebrew University, Israel.

We hope to continue and push our journal forward in view of its vision and mission, namely, publishing clinical as well as innovative translational research, applying high standards of clinical and scientific reporting, leadership in the field of clinical hematology publications, accessibility to our authors and readers, shortening the time lag from manuscript submission to decision-making, recruitment of peer reviewers, raising the impact factor, and increasing the number of readers and manuscript submissions.

In line with our policy of keeping the high standards of our journal and in view of the rising number of manuscripts submitted, the journal's rejection rate is around $70 \%$.

I am happy to say that the impact factor has been steadily rising with a current impact factor of 1.313 .
We are pleased that the new sections launched in 2018 - "Patient Reported Outcomes" and "Interdisciplinary Perspectives in Hematology" - were "active" in 2019 and expect them to be even more so in 2020.

A special issue entitled "Iron Deficiency Anemia Management in Different Clinical Settings" edited by Dr. Anat Gafter-Gvili and Dr. Michael Auerbach was published in May 2019, comprehensively covering the interdisciplinary aspects of iron deficiency in various disorders.

In line with the previous initiative, the authors of the most cited article as well as the most contributing Editorial Board reviewers were awarded for their contribution and efforts.

Finally, a new and more modern peer review system (ManuscriptManager) was introduced and activated. We hope that this will improve the review process.

We are still facing several challenges including the ongoing need to recruit qualified reviewers, efforts to increase the publication speed, and endeavor to raise the impact factor. With the leadership of our Editorial Board and Editorial Office team, we hope to achieve these missions in the future as well.

On behalf of the Editorial Board, I would like to thank our reviewers and contributors for their efforts and to encourage our readers to keep on with submission of the fruits of their professional work to Acta Haematologica. 